\title{
LA DICTADURA Y LAS ENFERMEDADES DE LA LUZ*
}

\author{
Pablo Blas Corro Penjean**
}

\section{Resumen}

A base de una investigación en curso sobre manifestaciones históricas y culturales de la conciencia de la luz en Chile como materia prima retórica (literaria, fotográfica, cinematográfica) de discursos sobre una modernidad local, el presente texto expone perspectivas filosóficas, literarias, sociológicas y cinematográficas sobre la dictadura de Pinochet unificadas por el diagnóstico estético de un tiempo y de ambientes afectados por lo que denominamos "enfermedades de la luz".

Palabras clave: dictadura, luz, enfermedad.

\section{DICTATORSHIP AND THE ILLNESSES OF LIGHT}

\begin{abstract}
As part of an ongoing research Project about the historical and cultural manifestations of the consciousness of 'light' in Chile -considered as rethoric 'raw matter' in literary, photographic and cinematographic discourses regarding modernity at a local level- this paper presents philosophical, literary, sociological and cinematographic perspectives on Pinochet's dictatorship. All of these perspectives are unified by, and have a common ground in, the asthetic diagnosis of a time and a context affected by what we call the sickness of light'.
\end{abstract}

Key words: dictatorship, sickness, light.

Recibido: 15-01-2013 Aceptado: 06-03-2013

* Luz, Modernidad y Representación en Chile, 1910-2010: Aplicaciones retóricas de la luz en la fotografía, el cine, los discursos institucionales y los textos críticos, proyecto n¹110362 (2011-2012) del Fondo nacional de desarrollo científico y tecnológico, Fondecyt, del Ministerio de Educación de Chile. Los ejecutores de esta investigación, Pablo Corro (ejecutor responsable), Gabriel Castillo Fadic, y José Pablo Concha (co-ejecutores), académicos del Instituto de Estética de la Pontificia Universidad Católica de Chile, agradecemos a Fondecyt-Conicyt por evaluar, financiar y divulgar este proyecto.

** Chileno, Doctor en Filosofía, Instituto de Estética, Pontificia Universidad Católica de Chile, Santiago, Chile, pablo.corro@gmail.com 
Nos encontramos en Chile. La primavera comienza: una claridad difusa, que todo lo empuja trémulamente casi sin sombras hacia el primer plano, irradia algo cruel; no queda rincón alguno donde refugiarse, nos sentimos desamparados, expuestos no sólo a lo que sentimos como "luz", sino a un verdadero fenómeno cósmico. Los álamos tiemblan al viento, acariciados por una mano invisible, y su follaje verde adquiere tonalidades plateadas. La soledad aumenta el sentimiento de impotencia: es imposible "ver" este paisaje desde el punto de vista pictórico; existe ciertamente, y despliega ante nosotros sus tentaciones, pero ningún artista ha respondido jamás a su llamado. En verdad, pintores provincianos intentan falsificarlo de manera grotesca hasta convertirlo en un paisaje europeo (Grassi 8).

La luz de Chile hiere la sensibilidad del filósofo Ernesto Grassi ${ }^{1}$, según sus anotaciones en el libro Arte y $\mathrm{Mito}^{2}$. La mezcla de intensidad y difusión de la luz local, la falta de sombras, a la vez que niega el espacio como campo abierto, puesto que proyecta todo hacia el primer plano, como una representación bidimensional, lo abre como territorio colmado de claridad donde no hay refugio posible, como un ámbito de incómoda exposición elemental. El filósofo declara irrepresentable el paisaje del valle de Santiago, la imposibilidad de verlo pictóricamente es un efecto de la desmesura de la naturaleza, de la insignificancia de las presencias culturales, materiales, humanas, en relación con las medidas descomunales de la geología, precisamente de la Cordillera de Los Andes, la que por esa misma indeterminación y, de nuevo, por la crudeza de la luz, aparece sólo como objeto de consideraciones empíricas:

Afuera brillan acerados Los Andes, ardiendo en la nieve, mezclando las fuerzas de la luz: un crisol flotante en el cielo de cobalto. Me pregunto: ¿podría ser éste un paisaje alpino, similar al que nuestros pintores han reproducido? Pero la pregunta suena grotesca, hasta hiriente, pues habría que ser ciego para creer en tal parecido. Los Andes se yerguen aquí como un

1 Filósofo italiano (Milán, 1902-Munich, 1991). En 1928 fue discípulo de Martin Heidegger. Participó en 1942 en la fundación del Studio Humanitas de Berlín. Es autor de El problema de la metafísica platónica (1932. Bari: Laterza), El poder de la imaginación. La historia del pensamiento occidental (1979. Königstein: Athenaeum), Introducción a los problemas filosóficos del humanismo (1986.Darmstadt: Routledge), entre otras obras.

2 Primera edición, Kunst und Mythos. Rowohlt, Hamburg 1957. 
fenómeno puramente geológico, o como figuras arrancadas de un tratado científico. ¿Acaso su altura y apariencia tienen la menor relación con el medio, o con la ciudad moderna que se extiende a sus pies? No, pues la ciudad que yace como un hongo seco al lado de una duna, sobrenada ahora en esa luz como una hoja marchita (9-10).

No es asunto de este texto considerar que la imposibilidad pictórica que Grassi atribuye al paisaje chileno en sus ensayos de consideraciones fenomenológicas sobre la percepción artística, resulta de la estrecha relación que él establece entre cualquier paisaje y el paisaje europeo moderno, entendiendo éste como un patrón métrico, armónico de distancias, tallas y como un sistema convencional, lógico y jerárquico de luces. Nos interesa destacar los juicios que hace sobre la luz local a mediados de la década de los 60, en su paso por Chile y allegado a los poetas y arquitectos fundadores de la Escuela de Arquitectura de la Universidad Católica de Valparaíso. Queremos llamar la atención sobre los efectos luminosos nefastos que en su último párrafo se suman al desdibujamiento de los perfiles, a la negación del espacio, a la exposición uniforme: la intensidad incinerante, la potencia para presenciar, a lo que suponemos es Santiago, como un mero hongo seco. Según esta perspectiva es la propia luz de Chile la que impide ver el paisaje chileno como objeto de efectiva representación artística, su luz la que lo expone a la circunstancia de la anomalía de la apariencia cultural.

En la ya referida investigación Luz, modernidad y representación, hemos identificado estética y filosóficamente hitos históricos y culturales de la conciencia de la luz en Chile como materia prima retórica de discursos sobre las manifestaciones de una modernidad nacional presentes en el ámbito del ensayo cultural, de la fotografía y el cine. En este texto, y como una inversión imaginaria, ominosa, de las analogías ideológicas entre la Luz y el despliegue institucional de la razón, procuramos exponer los fundamentos, manifestaciones y sentido de la conciencia simbólica de una luz anómala, de enfermedades de la luz, que afectan la atmósfera de Chile, particularmente a los ambientes del mundo metropolitano, durante la dictadura de Augusto Pinochet, pero proponiendo antecedentes poéticos, filosóficos y metáforas sociológicas de estos fenómenos, asociando así a la circunstancia histórica otra de trascendencia ontológica. 
En el orden de las poéticas audiovisuales, tales afecciones se advierten con nitidez en la mermada ficción cinematográfica chilena del periodo 1973-1990, especialmente en los filmes Julio comienza en julio, de Silvio Caiozzi (1979), El zapato chino (1976-79), Los deseos concebidos (1982), y El último round (1983) de Cristián Sánchez, y con literalidad pasmosa en algunos documentales de esos años, particularmente en Recado de Chile de Guillermo Cahn, Carlos Flores y José Román (1979). Este paradigma luminoso enrarecido también ha sido propuesto como un índice retrospectivo de caracterización política, tecnológica y sicológica de Chile durante el gobierno de Augusto Pinochet en la trilogía fílmica que constituyen contemporáneamente Tony Manero (2008), Post Mortem (2010) y No (2012), del cineasta Pablo Larraín. Concluiremos este ensayo examinando la caracterización retórica de la "luz enferma" de la dictadura, como articulación nefasta de la dupla luz/modernidad, en base a la película de Caiozzi y al documental Recado de Chile.

\section{Apertura, luz y ceguera}

Un factor dramático común en el corpus general de las películas que indicamos es el del encierro. La segregación cultural y política respecto del resto del mundo que afecta a Chile tras el derrocamiento de Salvador Allende, el sistema de vigilancia y represión que impone el gobierno militar a las poblaciones, estimula en el cine chileno el desarrollo argumental de los tópicos de las constricciones que imponen las autoridades, los límites de las clases sociales, el cerco que representan para las voluntades las instituciones rectoras, la reclusión doméstica como reacción fóbica al exterior, y la progresión abismal del encierro en la vivienda a través de la sumisión enajenada a la pantalla de la televisión. La dictadura proscribe la vida exterior. El "toque de queda", como medida de restricción judicial del derecho de circulación pública, suprime la calle como espacio de expresión y cultura, de congregación libre de sujetos, y el correlativo deber de cierre temprano de los establecimientos de actividad y esparcimiento nocturno torna la noche más estrecha, más densa, por el deber del recogimiento. La noche se convierte, para el cine y otras manifestaciones artísticas, en la dimensión existencial, cósmica, simbólicamente caracterizadora del estado de Chile durante la dictadura.

Sila dominante dramática de este sistema representacional es nocturna, ¿por qué introducimos estos planteamientos con el texto de Grassi referido a vistas diurnas, espacios abiertos, planos generales? Porque 
corresponde a un precedente históricamente inmediato a la imagen o sentimiento generalizado de la noche cultural y sicológica del Chile postgolpe, a uno de varios precedentes fenomenológicos, estéticos, de orden esencialista, que en los tiempos de un sentir nacional mayoritariamente identificado con la conquista popular de lo público, de la apropiación de los exteriores, definen a los chilenos como una nación que se resguarda de la luz. Los cuadros de Ernesto Grassi compuestos a fines de los 60 en Chile, efectivamente ignoran la existencia de pobladores en el territorio y figuran con sentido de ruina o brote inviable la presencia cultural de la ciudad seca. La especie de reducción fenomenológica que ensaya ante el paisaje extraño el filósofo, presentándolo tanto como a-histórico o prehistórico, para descubrir sus cualidades fundamentales de espacialidad y luz, para discernir sus propias facultades de inteligibilidad estética ante éste, concluye en que su claridad calcina, fuerza al refugio, que por difusa su luz desdibuja las formas, que suprime la apertura precipitando en el primer plano, que impide ver. El sentido arcaico de la descripción de Grassi, remota por esencialista, por la voluntad de discernimiento de lo original, por su patrón plástico pre-contemporáneo, por su enfática extranjería, infiltra factores nocturnos al paisaje exterior diurno del valle central chileno y lo somete a una intencionalidad intimidante, que causa miedo y promueve el resguardo sombrío: "Desde el pequeño cuarto en que estoy sentado, me siento resguardado en la penumbra de la pieza, en este ambiente de cuadros familiares, como los interiores de Matisse" (9). La inclinación por la oscuridad puede considerarse retrospectivamente como una intuición de la noche.

Entre 1951 y 1972, el filósofo y esteta chileno Luis Oyarzún escribe diversos textos, la mayoría de ellos integrados en su Diario y en el libro Defensa de la Tierra, en los que viajando por Chile advierte relacionadas la pobreza económica de la nación con un "pauperismo de la conciencia sensible". Dice de Chile que "este pueblo no tiene el sentido de la belleza" y ya sea en casas pobres de Santiago, en viejos solares aristocráticos convertidos en conventillos, o en ranchos sureños, se sorprende de la falta del más mínimo ornamento, del desdén por el exterior y por los valores de luz local, de la tendencia a encuevarse, y de la omnipresencia de residuos: "polvo, hollín huesos y trapos tirados por el suelo, piedras grisáceas, hierbajos secos". Un apunte del 2 de enero de 1951 dice de la capital:

Esta es la ciudad del polvo, pero no es este el polvo dorado de Castilla. Es un polvo gris, como el cemento molido de La 
Calera ¿De donde viene? Visto desde el aire, Santiago parece una cantera enorme que produce estupor en los viajeros que llegan de ese modo por primera vez. ¿Cuándo se comprenderá que hay que preocuparse también del aspecto que las ciudades presentan desde el aire? (113).

Sólo seis años después de este texto el sacerdote jesuita y cineasta Rafael Sánchez, cuando en su documental Las callampas (1957) denuncia la existencia de miserables asentamientos humanos en las riberas céntricas del río Mapocho, también convoca la vista aérea de la ciudad, mediante el registro desde una avioneta, para ilustrar su apariencia moderna, y para ofrecer con sentido cuantitativo, de geomensura social, el vasto llano periférico donde se levanta la población La Victoria, terreno "tomado" heroicamente por miles de pobladores que se rebelan contra su confinamiento en los campamentos ribereños. Aun cuando la representación de Sánchez está destinada a un espectador local, a un chileno que necesita que se le ataque su ceguera social, no difiere de la de Oyarzún en la producción de la imagen aérea de la "ciudad del polvo". Pese a la distancia de las perspectivas elevadas, en el caso de las de Sánchez y Oyarzún, y aun en la de Grassi que contiene el índice gráfico de la altura descomunal de Los Andes, se deduce que no hay posibilidad ascensional para los sujetos, los pobladores o los ciudadanos. Se los concibe instrumentalmente como parte del plano de lo rasante, lugar del polvo, del nivel de la ciudad hongo, de la ciudad deprimida, ciudad-cantera, equivalentes a la esparcida utilería residual que registra Oyarzún.

El movimiento de la conciencia simbólica hacia la concreción política de la imagen de la noche ha integrado en estas imágenes de los 50 la atmósfera difusa y deslumbrante por la mezcla de polvo y luz intensa, la alianza entre existencia menesterosa y déficit estético del ambiente y su habitante. El descubrimiento o la presentación inhóspita del elemento existencial atmosférico se articulan bien en Oyarzún con la caracterización subterránea de la nación chilena, precedente en el paradigma de "axiografías" 3 medioambientales al encierro que dominará desde 1973 hasta los 90.

3 "Axiografía" como escritura, o distribución retórica, de los valores en la configuración espacial del relato audiovisual según Bill Nichols en su libro La representación de la realidad (1997).

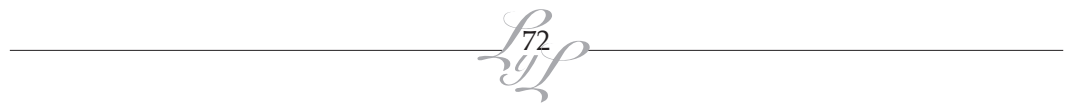


Quien ve un mundo de topos, no puede iluminar literariamente objeto alguno ni transformar estéticamente a la realidad. Por eso vivimos en ciudades de topos, habitables a lo sumo por ratones y arañas [...] En esas cuevas se crían niños. El aire no es más consolador, enturbiado desde temprano por el humo de los hornos crematorios de las orillas del río y de las fábricas del barrio Vivaceta. Hay que mirar a lo más alto del cielo para dar con un azul que parece inalterado. Más abajo del cénit solo seriedad y desaliño. ¿Será a causa de esto que los pintores chilenos, salvo dos o tres, pintan la luz con polvillo de cemento o lechada de cal? (...) aquí no se ha descubierto aún el mundo de los ojos. La gente ve con el estómago o con los órganos sexuales. (112-3)

La ineptitud de los chilenos para la luz natural corresponde al fallo de la luz-lumen, de la claridad del pensamiento humano, y tal defecto compromete tanto la razón estética, de ahí su énfasis en el desaliño arquitectónico, como la razón argumentativa, por ejemplo, en el orden de la política. Cada vez con mayor insistencia, a medida que las convulsiones políticas abrevian su frecuencia y elevan su intensidad en las dos décadas de escritura de su Diario (1951-1972), los bosquejos de la violencia social acompañan sus consideraciones fotográficas. Anota en abril de 1965: "Un estado de turpitud y de vacío ablanda los huesos, en el aire dorado del otoño. Bandadas de estudiantes apedrean autobuses." Pero el fallo chileno de esta luz-lumen, o en definitiva del logos, es también la ineficacia de su otra dimensión, la de la palabra, la que no logra describir las apariencias del propio mundo ni conoce los nombres de sus presencias. En uno de sus innumerables viajes, esta vez por la Araucanía, dice de los habitantes de sus pueblos que "son muy pocos los que conocen los nombres de los árboles o las flores y sólo la afición por la caza les permite denominar a los animales más comunes" (122), y conforme a este parecer tampoco los literatos aventajan a la gente común. A Manuel Rojas, a quien en su diario califica como "uno de los mejores narradores que existen en lengua castellana", reclama que:

la atención que dispensa a la naturaleza [...] en Hijo de Ladrón es insignificante [...] no se nombra aquí ni a árboles, plantas ni pájaros por sus nombres particulares [...] No encuentro nada más semejante a la atmósfera que este libro crea que la del cine italiano de post-guerra. (182) 
La conciencia chilena reñida con la naturaleza a través de los ojos busca el interior, cultiva la oscuridad, y el órgano de la palabra, la boca, sustituye el fallo verbal a través de una apropiación digestiva del mundo, reforzando el contacto con el afuera a través de la pertenencia interior, de una modalidad del consumo de las existencias naturales. Es muy elocuente al respecto su texto titulado "El mundo entra por la boca", escrito en Puerto Montt, el 14 de marzo de 1951:

En este momento me sorprende la gran tristeza de un mundo austral frío, carente de intimidad humana. Si los chilotes y sureños tuvieran una intimidad más poderosa, habrían sentido la necesidad de arreglar más confortablemente sus casas y hoteles, que son páramos en una comarca en que abunda la madera y la noche es larga. Se calientan comiendo y bebiendo en habitaciones oscuras. No hay acá el sentido flamenco del interior. Se vive para el aire libre o para el intestino, para el interior del cuerpo. Se amuebla el interior del cuerpo. El mundo exterior no entra por los ojos sino por la boca. (116)

En este tratado autobiográfico sobre las facultades, atrofias y prioridades cognoscitivas de los chilenos respecto de su mundo natural, Oyarzún adelanta las conexiones nítidas que la filmografía de Raúl Ruiz, en tiempos de la Unidad Popular, y a continuación la de Silvio Caiozzi y Cristián Sánchez hasta fines de los 80, establecerán entre el estado de clausura, el imaginario digestivo, la obsesión gastronómica y escatológica, la intensificación libidinal y el habla digresiva como lengua anómala. Con retardo y visión reminiscente, o a modo de tributo, Pablo Larraín repetirá en su trilogía fílmica la misma mezcla entre ambiente, cuerpo y conciencia.

El reconocimiento material digestivo y sexual en el interior oscuro refuerza en la caracterización de esta doctrina de las anomalías o enfermedades de la luz en Chile el componente de des-diferenciación figurativa, de debilitamiento de los perfiles singulares. Esta indicación permite restituir nuestra atención al fenómeno consignado originalmente de una atmósfera saturada de luz y polvo que difumina las formas y homogeneiza sus particularidades cromáticas.

Cuando Oyarzún comparaba la descripción de los ambientes humanos, de la existencia urbana que hacía Manuel Rojas en Hijo de ladrón y la asimilaba a su impresión de la atmósfera del cine italiano de 
post-guerra se refería a una "análoga efervescencia de la vida espontánea, de naturalidad en las relaciones humanas, de humanidad que baña la rudeza, la aparente vulgaridad, la miseria de los protagonistas" (182-3). En términos fotográficos, tal naturalidad compartida es la ausencia de jerarquías lumínicas, de dramatizaciones o metáforas atmosféricas. El cine italiano de post-guerra al que se refiere el filósofo es el "neorrealismo italiano" ${ }^{4}$, movimiento que se convertirá en una poderosa influencia estética e ideológica para el desarrollo de los nuevos cines latinoamericanos, entre otros para el "nuevo cine chileno". La luz del neorrealismo y de sus movimientos de réplica es reconocida por su naturalidad, por la uniformidad lumínica de la realidad exterior cruda.

Fabrice Revault D'Allones, en su libro La luz en el cine (2003), califica la estética fotográfica del neorrealismo italiano como parte del sistema de la "luz moderna". Como una:

actitud que percibe la luz del mundo como un continuo homogéneo, relativamente indiferenciado, neutro. De una neutralidad que, sobre todo, se opone decididamente a la teatralización clásica; del mismo modo que se opone a su manera a la otra vía evocada, la del realismo en estado bruto [que plasma la heterogeneidad de las luces existentes en el mundo] (38-9).

El tránsito pálido del formato fílmico de $16 \mathrm{~mm}$ al magnético U-Matic, que caracteriza técnicamente las condiciones del audiovisual en la dictadura, se identifica muy bien con la neutralidad, la homogeneidad de la llamada luz moderna. Si es admisible postular que la apatía luminosa cinematográfica de la dictadura chilena podría tener, entre otras razones, la del mismo desencanto epocal, la del mismo escepticismo que practica fotográficamente el neorrealismo frente a la razón y sus instituciones, podríamos hacer circular ese argumento por los cuadros y los tiempos que han descrito e interpretado Oyarzún y Grassi para sugerir que hay en las enfermedades de la luz chilena no sólo un componente de identidad sicológica o cultural local, no sólo una atrofia congénita, sino también un factor ideológico o psicológico transcultural y transhistórico: el del desencanto moderno.

4 De acuerdo con innumerables teóricos del cine tales como G. Sadoul, A. Bazin, G. Deleuze, N.Bürch, R. Barthes, o A. Martin, este movimiento representa, como relevo crítico del paradigma clásico, hollywoodense, de la apología espectacular del trabajo-acción, una alternativa moderna basada en la representación escéptica, escasamente activa y des-estilizada del mundo circundante. 
Para completar el inventario de la sintomatología estética de las enfermedades de la luz que propone Oyarzún y que nos servirán como elementos de identificación crítica y de exégesis ontológica de los fenómenos morbosos de la conciencia simbólica de la luz de la dictadura, rescatamos los motivos asociados de atmósfera y polvo para introducir la conciencia de un nuevo agente morboso, que se integra a estos factores aún naturales como un efecto nefasto de la prioridad mercantil, consumista y técnica que promueve el régimen militar a través de su ideario económico liberal. Nos referimos al smog de Santiago.

En el libro Defensa de la tierra, publicado en 1973, y que corresponde a un extemporáneo reclamo estético ecológico de orden ensayístico, en el capítulo "El smog de Santiago", Oyarzún se refiere a la contaminación del aire de la capital. El filósofo describe las impresiones que retuvo del fenómeno en una oportunidad que contemplaba la ciudad desde lo alto del Cerro San Cristóbal en compañía del entonces Presidente de la República Eduardo Frei Montalva y de su canciller Gabriel Valdés Subercaseaux:

Casi todos los días, en Santiago el habitante sufre, consciente o inconscientemente, la falta de paisaje, la asfixiante plenitud atmosférica y urbana. Nubes de humo de los incineradores de los edificios y de las chimeneas industriales empañan desde temprano el cielo. Aun bajo cielos puros, los techos están siempre polvorientos. No hay adentro ni alrededor naturaleza, ni árboles, ni pájaros, ni flores. Todo está mustio, agobiado bajo el peso del polvo humano. Millones de seres humanos se agitan en esta ciudad seca, entenebrecedora, árida, sin río ni mar en que descansen el ánimo y la vista. Los ojos se estrellan contra la piedra borrosa de la Cordillera y se duermen presos en la red de polvo y de sus radiaciones eléctricas, con el imán cordillerano por almohada (79).

La preocupación estética de Oyarzún coincide con el reconocimiento institucional de un problema de antigua data en la capital de Chile pero que se agravaba rápidamente. Justamente en 1970 fue creada la "Comisión nacional de descontaminación ambiental". Sin embargo, será en la década siguiente cuando sus manifestaciones y denuncias se intensifiquen. Mediciones de la calidad del aire realizadas entre 1977 y 1980 revelaron que el smog capitalino superaba cuatro veces los límites

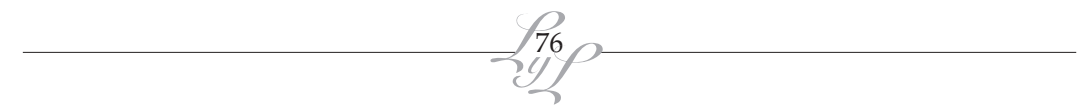


permitidos. En "Memoria chilena", portal web de la DIBAM (División de Bibliotecas, Archivos y Museos), en el texto La contaminación atmosférica de Santiago, se confirma la relación entre el Chile de la dictadura y el smog de Santiago:

En este contexto, la década del ochenta resultó clave y decisiva en la materia, ya que, al no mitigarse el problema de manera estructural, se alcanzaron los niveles históricos de contaminación más altos en Santiago. Esto se debió a que, si bien a través de la Constitución de 1980 se reconoció el derecho de todo ciudadano a gozar de un medioambiente libre de contaminación, por otra parte, se liberalizó el suelo y el transporte urbano, lo que repercutió directamente en los elevados índices de contaminación. ${ }^{5}$

En junio de 1988, año del plebiscito, en el número 165 de la "Revista Cauce", órgano editorial de oposición al gobierno de Pinochet, en el texto La contaminación de Santiago, los costos de la imprevisión, se exponen, con sentido retrospectivo, los resultados de un estudio realizado por el área de vivienda del "Instituto de Ciencias Alejandro Lipschutz" en el que responsabiliza del deterioro atmosférico al modelo económico instaurado por los militares:

Naturalmente no podemos modificar la configuración de la cuenca de Santiago ni las condiciones meteorológicas, pero el incremento de la contaminación ambiental ha sido una consecuencia inevitable de la aplicación dogmática durante quince años de un modelo económico mercantil, sin consideración alguna por el ser humano, lo cual ha agravado las situaciones críticas existentes con anterioridad, en especial la expansión descontrolada del área urbana y del parque automotriz. A esto se suma el agotamiento de los recursos forestales y de la escasez de áreas verdes, licitadas en algunos casos como "bienes de uso público prescindibles", y el descuido en la eliminación de los desechos sólidos e industriales, lo que ha generado un grave incremento en la contaminación de las aguas (44).

5 <http:// www.memoriachilena.cl/temas/index.asp?id_ut=lacontaminacionatmosfericadesantia go $>$, consultado el 10 de enero de 2013. 
La visión de Oyarzún, a fines de los 60, sobre el agente sólido que hace visible el aire y enturbia la luz de la capital, el smog, tiene efectivamente la categoría de mirada admonitoria puesto que en el sistema de la escritura filosófico estética chilena adelanta la consideración de un agente morboso que una década después, cuando el gobierno de Pinochet termine de sentar las bases de su modelo económico, comenzará a señalarse como un sello ambiental, atmosférico de la racionalidad liberal, mercantil de la dictadura, o, lo que es lo mismo, de su irracionalidad depredadora, de su tratamiento inhumano de las "existencias". Como última consideración relativa a los textos precursores de las enfermedades de la luz conviene destacar que en éstos el polvo y luego el smog se presentan como elementos que permiten "ver el aire" como medio de la luz pero también como soporte dañado. Una de las dimensiones de las anomalías de la luz cinematográfica en el cine chileno de la dictadura será la del soporte, de la película, base física, química, que reacciona y transcribe formalmente la luz y que, por razones estéticas o políticas, siempre determinadas por las circunstancias históricas de opresión, sufre una alteración.

\section{La noche y el "apagón cultural"}

En su novela breve Estrella distante (1996), Roberto Bolaño relata el devenir pre y post golpe de varios poetas chilenos reunidos originalmente como estudiantes de la Universidad de Concepción en diversos talleres de poesía. En el comienzo, el narrador entre diversos bosquejos sobre la escena literaria penquista, las filiaciones políticas de cada quien y las relaciones entre poesía y política durante la Unidad Popular, presenta como ejes de la comunidad a las talentosas y bellas gemelas Garmendia y a Alberto Ruiz-Tagle, personaje que desentona en el grupo por su elegancia, su aspecto aristocrático, y por no ofrecer referencias precisas sobre su actividad poética y académica. Poco después es sumariamente relatado el acontecimiento del Golpe, la desbandada y la frustración doble del narrador, quien se entera que las adoradas muchachas se destierran en su casa de campo en Nacimiento y que aman al misterioso poeta oligarca. El episodio de la irrupción del terror y de la noche, agentes simbólicos y sicológicos de la dictadura que hasta ese punto de la novela no tenían presencia dramática se desatan con la visita de Ruiz Tagle a la casa de las jóvenes. Después de cenar y leer poesía para agasajar al visitante, los comensales se duermen, el dudoso poeta se acuesta con una de las hermanas y regresa a su cama, más tarde se levanta otra vez, entra

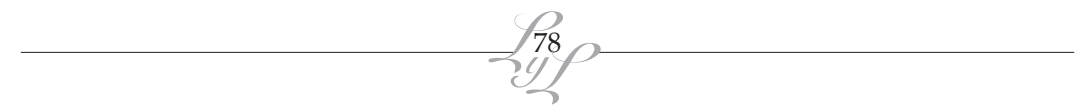


sigiloso en la alcoba de la tía de las jóvenes a quien degüella pulcramente con un corvo, luego, con la misma intención, busca a la empleada pero descubre que ésta ha huido y ya sin tiempo para corregir el fallo abre la puerta a unos hombres que han llegado en auto a la casa:

Estos saludan con un movimiento de cabeza (que sin embargo denota respeto) y observan con miradas obscenas el interior en penumbras, las alfombras, las cortinas, como si desde el primer momento buscaran y evaluaran los sitios más idóneos para esconderse. Pero no son ellos los que se van a esconder. Ellos son los que buscan a quienes se esconden. Y detrás de ellos entra la noche en la casa de las hermanas Garmendia. Y quince minutos después, tal vez diez, cuando se marchan, la noche vuelve a salir, de inmediato, entra la noche, sale la noche, efectiva y veloz. (32-3)

Después de ese acto, Alberto Ruiz-Tagle se revela como un agente de inteligencia del régimen y a la vez como un artista: pilotea aviones y escribe poemas con humo en el cielo, hace exposiciones fotográficas de cuerpos sometidos a sesiones de tortura. En la tertulia poética de la última noche de las Garmendia, éstas le piden al poeta-criminal que les lea algo, él rehúsa hacerlo, dice que prepara algo nuevo, Bolaño o el narrador expresa que "está a punto de nacer la "nueva poesía chilena'". En esta imaginación literaria fotográfica de un umbral histórico, la transición paradigmática del día a la noche figura el paso de la democracia a la dictadura a través de la erradicación violenta de un ámbito artístico y la emergencia de una nueva cultura chilena que colabora con el régimen y que se presenta con caracteres espectaculares.

Una efectiva escena de luz particularmente erradicada por la dictadura es la cinematográfica. Las anomalías fotográficas que distinguen a las películas del periodo, particularmente al largometraje de ficción Julio comienza en julio y al documental Recado de Chile, cifras estética y política, respectivamente, de la proscrita y jibarizada escena fílmica local, se relacionan de manera refleja y fáctica con un diagnóstico sobre el estado de retroceso general de la cultura chilena durante la dictadura que se denuncia por esos mismos años, que se convierte en un lugar común del diagnóstico sociopolítico de lo nacional, y cuya nominación constituye una metáfora conceptual luminosa del decaimiento espiritual. Nos referimos a la noción de "apagón cultural". 
En el artículo títulado En torno al apagón cultural, publicado en la revista Mensaje no 264 en 1977, el autor, Tomás Valdivia, señala que se trata de un asunto que ha sido "repetidamente aludido en los últimos meses", con otras denominaciones como "apagamiento cultural" o aun "vacío cultural", y con el que "no se está aludiendo principalmente a un fenómeno individual, sino a una problemática colectiva que se refleja en indicadores sociales y que trasunta en una enfermedad de nuestra convivencia nacional" (619). La sintomatología recuerda las afecciones de la conciencia señaladas antes por Oyarzún, afecciones de las facultades de inteligibilidad, de expresión y de dominio espiritual del espacio. Valdivia entrega datos sobre el retroceso de los niveles de lectura entre los chilenos ${ }^{6}$, sobre el deterioro del lenguaje, y sobre la concentración de la cultura a causa del fenómeno político económico, de su "privatización y atomización" en favor de las clases pudientes. Causas inmediatas de las afecciones lingüísticas de los chilenos son el aumento exorbitante del precio de los libros por los nuevos impuestos que los gravan, la correlativa disminución de las publicaciones, y la influencia creciente de la televisión, que en opinión del autor "posee un inmenso potencial educativo, pero se ha desvirtuado ajustándose a un estrecho criterio de mercado que [...] 'da gusto al mal gusto'”' (618).

Un año antes de la reforma educacional impulsada por Pinochet que desarma la educación pública, el texto apunta también contra las escuelas. En éstas, dice que "no se enseña ni se exige una buena capacidad de expresión: no se fomenta el gusto; se han descuidado 'las humanidades'” (p. 618). A través de las conexiones entre las universidades chilenas y esta "enfermedad de la convivencia" o "apagón cultural", Valdivia descubre las causas políticas y otros efectos sociales donde se inscribiría también la desaparición del cine chileno:

A estas denuncias se suman otros problemas que no podemos olvidar. El de las universidades [...] el del éxodo de los profesionales, sea por motivos económicos, sea por depuraciones en las que -al decir de El Mercurio- "primó un criterio estrecho... prevaleció la seguridad ideológica a la seguridad del saber auténtico" (página editorial, 3 de octubre,

6 "Cada día se lee menos en Chile. Las ediciones nacionales han decaído considerablemente: de 1497 títulos editados en 1965 se ha llegado a 618 en 1975; de 12.000 dólares gastados en 1969 en importación de libros y revistas se llegó en 1976 a sólo 3.400" (618). 
1977); la consiguiente dispersión de equipos humanos; la diáspora de artistas chilenos, que antes animaban nuestro medio y ahora recorren el mundo; la disminución del gasto público en educación y en investigación científica y tecnológica. (618)

El autor somete la restricción autoritaria del derecho social y popular de la deliberación acerca del sentido de la política y la cultura a los efectos más generales del funcionamiento de la sociedad chilena como "sociedad disciplinaria". Explica Valdivia que "las normas y valores nacionales no son ya el fruto de la elaboración cultural de los chilenos, sino 'disciplinas' impuestas que fijan el límite de lo permitido y lo prohibido, de lo pensable y lo delictual" (p. 620). Estas disciplinas no son efecto sólo de la institucionalidad política sino también de la mediática y la económica, o en un sentido más abarcador, de la institucionalidad prioritariamente mercantil. Conforme a este régimen de existencia, la cultura chilena sufre diversas "distorsiones" unificadas por el componente de restricción, encierro e imitación. Sobre este último efecto dice el articulista:

Es una falsificación de la cultura, presente hoy entre nosotros, el relegarla al terreno de lo ornamental y lo superfluo. También lo es el reducirla a un arte desnaturalizado de sentido destinado a ser manoseado como cosa bonita -por aquellos pocos chilenos que pueden preocuparse de la elegancia- o como fachada de altruismo y legitimación, por parte de las empresas más prósperas. (620)

Sobre el primer punto se expresa en el artículo que "otra distorsión de la cultura es la privatización y atomización. Al arrancarse la cultura de la esfera pública, ésta pasa a grupos determinados: élites, cenáculos, grupos de intelectuales que crean instancias de comunicación para debatir problemas de interés común" (620).

Respecto al segundo punto determinado por el miedo a las consecuencias policiales de la expresión, se extrema el recurso de la escena cultural cerrada y de una expresión en clave en el impulso de la autocensura: “No son mejores los ‘valores' que se siguen del autoritarismo. El chileno es un pueblo que puede acostumbrarse a callar: la autocensura del temor limita aún más un espacio de expresión ya estrecho" (621). 
La metáfora del apagón, a diferencia de la "entrada de la noche" concebida literariamente por Bolaño, o de la ciudad del polvo, o ciudad hongo seco calcinada por la claridad cruel, respectivamente imaginadas por Oyarzún y Grassi, contiene un elemento contemporáneo: el del fallo del suministro eléctrico, colapso del sistema de iluminación pública. Tal circunstancia, que se convertirá en un acontecimiento común en la década siguiente, puesto que la insurrección de la población civil va a aparejar el derribamiento de torres de transmisión eléctrica para oscurecer la ciudad, entorpecer la acción policial y represiva del régimen, y para exteriorizar operativamente la inestabilidad de su poder, conecta simbólicamente con el corte súbito del suministro de la cultura, y como compensación, con el encendido de la televisión como surtidor cultural espurio. Pero la metáfora es también una imagen de plano general, se conecta con las impresiones del espacio abierto enturbiado por el smog y con las consideraciones de sublimidad espacial e intemperie que caracterizaban a los cuadros de Grassi y Oyarzún. En todos estos casos, estas conciencias estético-políticas descubren simbólicamente el espacio abierto, la atmósfera como una dimensión de inquietud, de angustia de exposición, de vulnerabilidad, de sentimiento de exposición social y cultural, de asedio policial. A la vista del apagón hay que agregar las nociones de "depuración política" y "seguridad ideológica" que aluden eufemísticamente a la represión violenta del régimen militar contra los detractores.

Peter Sloterdijk, en Burbujas (2003) y Temblores de Cielo (2003), plantea que una deriva ominosa de la voluntad espiritual de la modernidad de construir esferas de intimidad y de inmunidad, que reparen imaginariamente el sentimiento astronómico de intemperie y marginalidad que provoca la teoría de Copérnico, es la de concebir el medioambiente espacio abierto, medio aéreo, atmósfera como dimensión insegura, ámbito de exposición, flanco de agresión, territorio de vigilancia. El filósofo descubre el espacio abierto como un fallo en la ilusión de hermetismo de las naciones modernas.

En los diagnósticos simbólicos sobre el devenir del medio ambiente físico, cultural e ideológico chileno desde comienzos de los 50 hasta la dictadura, reconocemos el giro ominoso de la consideración del espacio abierto, de la atmósfera por el despliegue creciente de tensiones políticas, la acción de agentes contaminantes, el declive de las facultades estéticas, y la acción disciplinaria del estado en la vida pública, o sea, a través de 
las manifestaciones locales del ajuste a una modernidad protectora que deviene siniestra. La sensación inquietante del afuera se expresará en el cine chileno referido a través de la prioridad argumental del encierro y de diversas manifestaciones del lenguaje dañado, que incluyen esa reacción cultural nefasta de los chilenos a la disciplina, la "autocensura" o el "callar".

\section{Julio Comienza en Julio (1977) y Recado de Chile (1979): daños en la piel luminosa}

Las estructuras de intimidad, como tópicos tradicionales del melodrama costumbrista, se convertirán en estructuras de encierro tras el golpe de Estado. La erradicación casi absoluta del cine del medio cultural y social chileno es relativizada a través de realizaciones, a pesar de todo, de carácter crítico, pero licenciadas en lo político mediante una argucia representacional, la del ajuste a tópicos cinematográficos clásicos.

El relato de encierro que funciona como representación a escala de una sociedad vigilada, de un Estado autoritario, podrá blanquearse políticamente a través de sus ajustes a los temas de la familia, del culto religioso, de la insularidad geográfica, un poco menos, de las dialécticas interclases. Pero también será una forma justificada comercialmente por sus parentescos efectistas con el mundo del melodrama. Julio comienza en Julio (Caiozzi, 1977) precede el éxito, o se plantea como una réplica de la fórmula del melodrama televisivo histórico, como la célebre serie Martín Rivas, versión televisiva de Sergio Riesenberg (TVN, 1979) de la novela homónima de Alberto Blest Gana, o de La Quintrala de Sabatini (TVN, 1987). (56).

Así comienza el capítulo "La poética del encierro o el poder a escala" de nuestro libro Retóricas del cine chileno: ensayos con el realismo (2012). En este texto afirmamos que Julio comienza en julio es un melodrama, considerando que trata sobre las pasiones que se desatan en una hacienda de la zona central chilena ${ }^{7}$ en la segunda década del siglo XX después del festejo que Julio García del Castaño, patrón viudo, brinda a su hijo único, Julito, por sus quince años. La fiesta de los señores, animada por

7 En las localidades rurales de Pirque y Calera de Tango al sur de Santiago. 
las prostitutas que viven en el poblado del fundo, casi como inquilinas, concluye con la iniciación sexual del unigénito, en el programado paso a su adultez, pero, conforme al esquema de amor/impedimento del melodrama, deriva en el amor del joven por la muchacha. El guión de Gustavo Frías contiene numerosos conflictos, externos e internos, remotos, próximos, mayúsculos y leves. Mientras el patrón resuelve en Santiago un litigio de tierras con unos curas vecinos, estalla en Europa la Primera Guerra Mundial, en la casa patronal la abuela agoniza, Julito desatiende sus deberes de amo y estudiante visitando a la María, su enamorada prostituta, unos animales de la hacienda se desbarrancan, y el preceptor de la casa, ahora sin actividad por los nuevos intereses de Julito, se subleva. Todos estos conflictos exponen el poder del patrón, poder económico, político, social y cultural absoluto sobre sus inquilinos, y relativo en relación a sujetos de otros estamentos: el burgués político y abogado que lo asiste en sus pleitos y a quien debe ungir para su candidatura a diputado, los curas que disputan sus tierras, y su propio hijo a quien no le seduce ni el poder, ni las cuestiones económicas, ni tampoco los avatares de la contingencia mundial. Las estrategias de solución de los conflictos que practica el aristócrata van desde la recuperación ilegal de las tierras que disputa, la amenaza al preceptor sublevado, y la demostración brutal al hijo del carácter de cosa, de la mujer pretendida. En la escena final, el padre se las arregla para que Julito lo vea poseyendo a su amada María. Pese al poder que revelan, a la fuerza desplegada, estas acciones no son eficientes y se advierte que la autoridad absoluta del patrón declina; aun más, que el mundo de la hacienda chilena aristocrática y la estructura estamental que la soporta desaparecen ante el empuje de la mesocracia, de la técnica y de diversos agentes ilustrados. En 1977, esta historia de poder absoluto, de encierros, de vigilancias, de deseos frustrados, de sometimiento de todas las existencias a la voluntad del Gran señor, no podía no referir el estado general de la nación chilena sometida al gobierno militar, y en particular sujeta al poder despótico de Pinochet. A tres años del golpe militar, la situación del gobierno era inversa a la de un poder declinante pero la presentación repelente del autoritarismo nacional era indesmentible y sus referentes indudables, y el tópico del cambio de sociedad también era una alusión histórica indirecta. Pese a sus representaciones de la autoridad, la película sorteó el examen de la basta censura del régimen que proscribía alusiones políticas literales, y considerando el ajuste argumental y dramático 
del filme a los esquemas inocuos del melodrama, y los ingredientes de interés mercantil de su propuesta, como el erotismo y la presencia de actores de televisión, no mereció objeciones y probablemente contribuyó al reposicionamiento y éxito de los melodramas de época en la televisión chilena. La caracterización fotográfica de este sistema de relaciones de poder, caracterización foto-axiográfica más bien, en el sentido que se trataría de una trasposición luminosa de los valores en el espacio, coincide en términos estéticos con lo que Revault, teórico de la luz en el cine, llama "luz clásica", la que se caracteriza por la metaforización global de sus aplicaciones, su jerarquización y legibilidad dramática. A través de la opción por la monocromía y la relación polar de clarooscuro, Caiozzi construye un mundo de encierros sin término, encierros contiguos contenidos por el gran sistema de clausura que es la hacienda. La habitación del hijo, el salón señorial de la casa, el escritorio del padre, la cocina de la servidumbre, el prostíbulo y sus habitaciones sin aire, la casucha de los encuentros sexuales entre Julito y María, el baño turco del patrón, figuran como continentes cerrados de luz y oscuridad, donde esos valores se distribuyen conforme a un criterio de jerarquías y se relacionan ampliando o restringiendo las formas según la capacidad efectiva de cada personaje de dominar el espacio y su razón de existencia. Una escena de jerarquización y metaforización global de la luz es aquella en que el padre, de vuelta de su viaje de diligencias legales, interroga al hijo sobre el estado de la hacienda.

El monólogo del padre con el hijo, afección política del lenguaje que restringe su despliegue a los modos conativos del patriarcado filial y religioso, a los sermones de este padre y del cura, ocurre en un cuarto oscuro donde el hombre toma un baño de cajón. En la oscuridad, sin límites del espacio cerrado, se advierte tenue en un segundo plano la figura de Julito de pie y en el centro inferior del cuadro deslumbrando asoma la cabeza de Julio padre de la superficie del baño de cajón. La jerarquía no es espacial, es luminosa, la intensidad de la luz del padre se impone a la elevación sombría del hijo, la metáfora luminosa es la de un padre-sol, cabeza habladora, lámpara baja atemorizante.

Conforme al relato de Frías y a la puesta en escena de Caiozzi, a pesar de que hay espacios abiertos, arboledas, patios señoriales, potreros, los personajes están condenados a la noche o a los interiores, la padecen como una restricción de la autoridad, la prefieren como el remedo de un arraigo en una tierra que no les pertenece, o porque como intimidad es 
oportunidad de expansiones sensuales. Esta interioridad aplastada por la hegemonía del hacendado, por los pregones del pecado del párroco, por los quejidos de los moribundos, por las imágenes tenebristas y barrocas de los cristos y los demonios coloniales, es el mundo de los topos de que hablaba Oyarzún. Sin embargo, la inclinación morbosa por los interiores y la oscuridad, mezcla de ágora y fotofobia, no es la principal alusión fotográfica patológica a la dictadura.

El filme de Caiozzi no es realmente en blanco y negro sino que en sepia. El virado químico de la imagen a esa tonalidad café, no obedece a la función técnica original de asegurar la conservación de la imagen sino a la producción del efecto estético, ideológico, de una impresión luminosa envejecida, de una representación descompuesta, eventualmente de una atmósfera polvorienta y ruinosa. Este es uno de los casos anunciados donde la alteración química del soporte luminoso hace ver la descomposición atmosférica del cuadro histórico constreñido por la autoridad, las afecciones por encierro del aire y la luz del país de referencia. Otra relativa anomalía de la luz de Julio comienza en julio se manifiesta precisamente en su doble oposición física a la luz electrónica de la televisión, medio que la dictadura privilegia por esos años como agente difusor de su doctrina del bienestar a través del consumo, como apaciguador social eficiente, penetrante, con capacidad para abrir en cada casa un espacio dramático variado compensatorio de los controles internos del espacio real y del cerco político que el mundo opone a Chile.

Entre el año de estreno de la película de Caiozzi y 1979, año de realización clandestina y sin créditos del corto documental Recado de Chile, la comunidad internacional rechaza las violaciones a los derechos humanos que comete el gobierno militar contra la población civil desde el 11 de septiembre de 1973 en adelante. Tal como señala el narrador over del documental en su obertura, la Comisión de Derechos humanos de las Naciones Unidas condena:

las constantes y notorias violaciones a los derechos humanos que han ocurrido y continúan ocurriendo en Chile, en particular la práctica institucionalizada de la tortura y la desaparición de personas por motivos políticos. La comisión insta a las autoridades chilenas a que pongan fin a la práctica inadmisible de las detenciones secretas y ulterior desaparecimiento de personas cuya detención es denegada sistemáticamente o nunca reconocida (1979). 
Además de los miles de ejecutados políticos, torturados y detenidos desaparecidos, cuyos familiares se organizan a fines de 1974 para esclarecer sus paraderos y reclamar justicia, la comunidad nacional e internacional se conmociona por los asesinatos del general Carlos Prats, ex comandante en jefe del Ejército de Chile durante Allende, y de su señora en Buenos Aires en 1974; el atentado contra el ex ministro del Interior del Gobierno de Eduardo Frei Montalva, Bernardo Leighton en Roma, en octubre de 1975, y el asesinato del ex canciller y ministro de Defensa del Presidente Allende, Orlando Letelier, mediante la detonación de un artefacto explosivo instalado en su vehículo en Washington ${ }^{8}$. Pero quizá el acontecimiento que más afecta la conciencia nacional, al punto de activar arriesgadas reacciones públicas de repudio y el compromiso efectivo de la Iglesia Católica con las víctimas de la represión y con sus familiares a través de la Vicaría de la Solidaridad, encargada de prestarles auxilio y asistencia judicial, fue el hallazgo de 15 cuerpos de ejecutados políticos en unos hornos de cal en la localidad de Lonquén 9 .

En relación con este contexto, el cortometraje documental Recado de Chile, a la vez que difunde la condena mundial contra el Estado chileno, presenta las acciones organizadas de la Agrupación de Familiares de Detenidos Desaparecidos (AFDD), una huelga de hambre realizada en junio de ese año por sus integrantes y colaboradores, las actividades de sus grupos folklóricos y las acciones de esparcimiento e intervención terapéutica para los niños de las familias afectadas. Ya sea mediante el expediente de la presentación de fotografías de los detenidos desaparecidos acompañadas por el relato de una voz over que precisa sus identidades y circunstancias, o a través de las entrevistas a los parientes organizados, que detallan los antecedentes de sus familiares y las circunstancias de su detención o desaparición, el documental enfatiza la situación inubicable de estas personas y su condición existencial incierta, a la vez que las referencias visuales y nominales de ellos en el filme se difunden como recursos para su búsqueda e identificación.

8 Cfr. El capítulo XII, “Con mano militar", particularmente el apartado "una herida abierta" (287-290) del libro Historia del siglo XX chileno de Sofía Correa; Consuelo Figueroa; Alfredo Jocelyn-Holt; Claudio Rolle y Manuel Vicuña. (2001). Santiago de Chile: Editorial Sudamericana.

9 En 1982, usando un heterónimo para resguardar su identidad, el documentalista Ignacio Agüero presentó el documental No olvidar que se refiere a estos hechos y corresponde probablemente al primer crimen político post golpe que impresiona luminosamente la conciencia cinematográfica documental de Chile. 
Las anomalías de la luz que contiene este documental, que contra lo previsto es muy luminoso, proclive a presentar los hechos y a sus figurantes en emplazamientos exteriores, en espacios abiertos con luz natural, tienen que ver con el deber de invisibilidad delos documentalistas. Pese a ser evidentemente un documental de interacción, puesto que se ve un micrófono en una mano que surge desde el lado de la cámara para captar los testimonios, las respuestas de los familiares de los detenidos desaparecidos, la presencias sonoras y visuales de los documentalistas fueron borradas. Sus voces que preguntan, como parte de ese mismo mundo diegético, el registro sincronizado de sus manifestaciones verbales, fueron silenciadas, segregadas de la mezcla en el montaje. El plan de ocultamiento de los documentalistas en el registro no fue perfecto y el montajista del filme, revisando el material en la moviola advirtió en segundo plano la figura reconocible de uno de ellos en los fotogramas de una escena. Con la plena certeza de que tal aparición ponía en riesgo la vida de esa persona y que su descubrimiento por agentes del régimen podía frustrar el proyecto de circulación propagandística y auxiliar del filme, los responsables del montaje en Cuba resolvieron borrar, hacer desaparecer, fotograma a fotograma la imagen del documentalista. En tal caso, adulteraron la continuidad, la fidelidad iconográfica y dramática de esos ambientes y situaciones, construida a través de la exposición indiscriminada de todas sus presencias a la luz, o en base a la acción figurativa sobre el soporte sensible de sus emisiones lumínicas.

Advertimos que existe una paradójica correspondencia en la película entre la dimensión argumental, testimonial, iconográfica de los desaparecidos por el régimen, y el documentalista que debe hacerse desaparecer de entre esas mismas imágenes para dar subsistencia al discurso. Unas y otras desapariciones son efectos de la violencia del gobierno militar, corresponden a presencias y ausencias luminosas que reaccionan a sus apremios. La dictadura produce veladuras, opacidades, borrones, fantasmas en la imagen.

En lo sucesivo, los efectos de las políticas del gobierno militar, de liberalización económica, apertura al intercambio comercial e impulso a la televisión, medio que servirá al régimen como agente de dinamismo mercantil y de control imaginario del país, afectarán la intensidad de la luz y de los colores de las películas. Los largometrajes de Cristián Sánchez, de la década del 80, ficciones coloquiales, risibles y ominosas del circunstancial encierro de Chile, asumirán en El zapato chino (1976- 
79) el sello fotográfico del blanco y negro debilitado del $16 \mathrm{~mm}$, como el canto del cisne del formato fílmico de los '60 y de la UP. Luego, en Los deseos concebidos (1982), la sobre-exposición luminosa y la estridencia cromática del cine sometido a la obsesión sensualista de la publicidad dominante, y por último, en El último round (1983) el colorido tenue, difuso y granulado de los primeros soportes magnéticos, particularmente del U-Matic, formato afín a la "pobreza" de la crisis del 82 y a la ilusión de acceso a medios de registro audiovisual que tienen grupos opositores al gobierno.

Dramáticamente inspirado en el cine de Sánchez y recreando tecnológicamente hoy sus condiciones de registro, Pablo Larraín propone la imagen desenfocada en Tony Manero (2008), la pálida y verdosa "luz fiscal" en Post mortem (2010), y el colorido electrónico "quemado" y que desborda las figuras en No (2012), como la esencial sintomatología fotográfica morbosa que caracteriza estéticamente a la dictadura de Pinochet y a un ambiente espiritual y sicológico de Chile que precedió, hizo posible y trasciende su régimen.

\section{Bibliografía}

Bolaño, Roberto. Estrella distante. Barcelona: Anagrama. 1996. Medio impreso.

Corro, Pablo. Retóricas del cine chileno: ensayos con el realismo. Santiago: Ediciones Cuarto Propio. 2012. Medio impreso.

El zapato chino. Sánchez, Cristián, dir. b/n. 1976-1979. Medio fílmico.

El último round. Sánchez, Cristián, dir. Color. 1983. Medio magnético, U-Matic.

Grassi, Ernesto. Arte y mito. Buenos Aires: Nueva Visión. 1968. Medio impreso.

Julio comienza en julio. Caiozzi, Silvio, dir. color. 1979. Medio fílmico.

Los deseos concebidos. Sánchez, Cristián, dir. Color. 1982. Medio fílmico.

No. Larraín, Pablo, dir. Color. 2012. Medio fílmico.

Nichols, Bill. La representación de la realidad. Buenos Aires, Paidós. 1997.

Medio impreso. 
Oyarzún, Luis. Defensa de la tierra. Santiago de Chile: Ediciones Universitaria. 1973. Medio impreso.

. Diario. Concepción: Ediciones Lar. 1990. Medio impreso.

Post mortem. Larraín, Pablo, dir. Color. 2010. Medio fílmico.

Recado de Chile. Cahn, Guillermo; Chaskel, Pedro; Flores del Pino, Carlos; Román, José, dir. b/n. 1979. Medio fílmico.

Revault D'Allones, Fabrice. La luz en el cine. Barcelona: Cátedra. 2003. Medio impreso.

Sin autor. "La contaminación de Santiago: los costos de la imprevisión". Revista Cauce. $\mathrm{N}^{\circ} 165$. Santiago: Tecnoprint. Junio de 1968. Medio impreso.

Sloterdijk, Peter. Esferas: Burbujas. Volumen 3. Madrid. Siruela. 2003. Medio impreso.

Sloterdijk, Peter. Temblores de aire. Valencia: Pre-textos. 2003. Medio impreso.

Tony Manero. Larraín, Pablo, dir. Color. 2008. Medio fílmico.

Valdivia, Tomás. “En torno al apagón cultural". Revista Mensaje Vol. XXVI, 264 (noviembre 1977). 18-21. Medio impreso. 